Brief Report

\title{
Covering Layers on Granite Buildings of Northwestern Iberian Peninsula: When Observable Characteristics and Lab Characterization Do Not Match
}

\author{
Patricia Sanmartín ${ }^{1, *(\mathbb{D})}$, Jorge Sanjurjo-Sánchez ${ }^{2}$ (i) and Beatriz Prieto ${ }^{1}(\mathbb{D}$ \\ 1 Departamento de Edafoloxía e Química Agrícola. Facultade de Farmacia, Universidade de Santiago de \\ Compostela, 15782 Santiago de Compostela, Spain; beatriz.prieto@usc.es \\ 2 Instituto Universitario de Xeoloxía, Universidade da Coruña, Campus de Elviña, 15071 A Coruña, Spain; \\ jorge.sanjurjo.sanchez@udc.es \\ * Correspondence: patricia.sanmartin@usc.es; Tel.: +34-881-814-984
}

Received: 2 January 2020; Accepted: 30 January 2020; Published: 4 February 2020

\begin{abstract}
Illustrated glossaries on stone pathologies help to describe deterioration forms in built heritage without resorting to any laboratory analyses. In this way, terms such as crust, deposit, and soiling which according to ICOMOS-ISCS: Illustrated Glossary on Stone Deterioration Patterns may include exogenic material, a patina which results from ageing of the material in an endogenous process, and a film included under the broad term of a coating layer in the glossary, can be macroscopically identified on site. However, a definition on the basis of characteristics only observable with the naked eye (without further analysis in the laboratory) is certainly complicated, and if in addition, the case studies are on granitic rock (a major building stone used across Europe), the picture becomes even more complicated. The intention of this brief report is to engender an open, constructive debate about the casuistry of the covering layers on granite (a poorly reactive and less porous rock) and the difficulty of using the ICOMOS nomenclature on them.
\end{abstract}

Keywords: decay phenomena and processes; granite buildings; urban areas; temperate weather; NW Spain; ICOMOS-ISCS glossary; stone deterioration

\section{Introduction}

The study of covering layers on stony materials is not new. As Dorn [1] remarked, there has long been historical interest in them, which deepened during the last century. Indeed, in the last 50 years, many studies of coatings on natural outcrops and historical buildings have been published. Because of this, in some cases, a broad but poorly structured and consensual terminology has been proposed to refer to different surface layers. Dorn's proposal of terms is based on microscopic and geochemical properties: the origin of materials, aspect, thickness, and composition. Furthermore, this author proposed the use of the term coating to group all of the coverings together and defines the term as a "mixture of materials accreted to the rock by physicochemical processes that are often biologically mediated", at the same time noting that the term was not standardized. While recognizing that the compilation should not be considered a systematic classification reference, Dorn suggested that it could be a first step towards unifying the proposed definitions [1].

On the other hand, and closer in context to the cultural heritage conservation researcher than to the geologist, there is the ICOMOS-ISCS: Illustrated Glossary on Stone Deterioration Patterns [2], a very useful tool for identifying and comparing decay phenomena on a visual basis. It appeared as a result of decades of work, after extensive analyses and discussions of terminologies and glossaries 
from multiple origins, such as in the Italian, French, German, and English language. One of the six categories included in the glossary ("Discoloration and Deposit") encompasses a series of terms relating to covering layers:

Crust is used to describe a "Generally coherent accumulation of materials on the surface. A crust may include exogenic deposits in combination with materials derived from the stone. A crust is frequently dark coloured (black crust) but light colours can also be found. Crusts may have an homogeneous thickness, and thus replicate the stone surface, or have irregular thickness and disturb the reading of the stone surface details";

Deposit is used to describe an "Accumulation of exogenic material of variable thickness. Some examples of deposits: splashes of paint or mortar, sea salt aerosols, atmospheric particles such as soot or dust, remains of conservation materials such as cellulose poultices, blast materials etc.";

Film is used to describe a "Thin covering or coating layer generally of organic nature, generally homogeneous, follows the stone surface. A film may be opaque or translucent";

Patina is used to describe a "Chromatic modification of the material, generally resulting from natural or artificial ageing and not involving in most cases visible surface deterioration" without perceivable thickness to the naked eye and often having a favorable connotation;

Soiling is used to describe a "Deposit of a very thin layer of exogenous particles (e.g., soot) giving a dirty appearance to the stone surface".

Both sources can be useful to describe covering layers on building materials. However, since sedimentary rocks such as limestone and sandstone are by far the most common type of building stone used, and because when dealing with porous rocks such as these, some exogenic materials can penetrate the rock; the result may be better described with the ICOMOS-ISCS glossary than with Dorn's nomenclature.

Facing this situation, it is worth wondering what happens with less porous (and poorly reactive) rocks such as granite, which is also a major building stone used across Europe [3], being very common in Galicia (NW Spain) and some surrounding regions (N Portugal), where mostly Paleozoic granite is the principal building material. Thus, the aim of the present study was to analyze the adequacy of the ICOMOS-ISCS glossary terms relating to covering layers in granitic rocks, based on the properties of this rock type. We illustrate this with six case studies taken in granite buildings of urban areas of the Galician cities of Santiago de Compostela and A Coruña, which are characterized by a temperate climate and no significantly high air pollution.

\section{Case Studies}

Six coatings formed on the surfaces of historical granite buildings of different ages, placed in different sites and exposed to different environmental conditions, were considered. The buildings are located in the cities of Santiago de Compostela and A Coruña (Galicia, NW Spain), both with an oceanic climate (a humid subtropical climate according to the Food and Agriculture Organization of the United Nations' agro-ecological zoning) with high atmospheric humidity caused by high rainfall and mild temperatures throughout the year [4], as well as no significantly high air pollution.

Sampling of coatings on buildings was performed in a similar manner to that described in Prieto et al. [5] and Sanjurjo-Sánchez et al. [6]. Because covering layers on building surfaces and façades are highly variable, analytical studies and techniques cannot be standardized. Consequently, different methods are used for the characterization of the covering layer in each case. For the present study, both surface and polished cross-sections of coating samples, which included the granite underneath the coating layer, were prepared and observed using scanning electron microscopy (SEM) by secondary and backscattered electrons, and X-ray maps in a JEOL JSM 6400 scanning electron microscope at $16 \mathrm{keV}$ coupled to a electron dispersive spectroscopic analyzer (EDS) Oxford 200 Inca Energy EDS at the University of A Coruña and a LEO-435VP at University of Santiago de Compostela.

Differences in the mineralogical composition of the coating layer and the granite underlying the coating were analyzed by X-ray diffraction (XRD) of the powdered samples, using a D5000 SIEMENS 
X-Ray Diffractometer at University of A Coruña and a PW1710 Philips diffractometer at University of Santiago de Compostela.

A Bruker IFS66 infrared spectrometer with an FRA 106 Raman module and Raman microscope attachment were also used. IR/Raman Spectra were obtained using an Nd:Yag laser of $350 \mathrm{~mW}$ and operating at $1064 \mathrm{~nm}$.

In all cases, a term relating to the covering layers was chosen from the ICOMOS-ISCS glossary based on an on-site visual assessment using the naked eye. Subsequently, that term was compared with the term that appeared according to the characterization made in the laboratory, using the aforementioned techniques.

Three case studies in the old town of Santiago de Compostela [7] were considered. The first concerns the exterior wall of a house (Number 2) in Toural Square $\left(8^{\circ} 32^{\prime} 42.0^{\prime \prime} \mathrm{W}, 42^{\circ} 52^{\prime} 39.6^{\prime \prime} \mathrm{N}\right.$, WGS84) on which a dark layer that is difficult to separate from the granite substrate had formed (Figure 1). It was identified on site as a patina according the ICOMOS-ISCS glossary. Further examination of samples of the material by electron microscopy revealed two layers of variable thicknesses: a superficial layer of thickness between 82 and $260 \mu \mathrm{m}$ and an inner layer of thickness between 50 and $470 \mu \mathrm{m}$ (Figure 1C). The inner layer was interspersed between the mineral grains and the diffuse boundary, making it very difficult to distinguish the material from the underlying rock. Furthermore, the covering layer was almost exclusively formed by inorganic particles (including gypsum crystals in their characteristic habit. Given that gypsum was present in the joint mortar, the most likely hypothesis is that it moved to the ashlar forming part of the layer). Element distribution mapping (Figure 1D) identified S and Ca as the main components (components of calcium sulphate, i.e., gypsum), with $\mathrm{Al}$ and $\mathrm{Si}$ appearing in the underlying granitic material [5]. Biological characterization did not show any evidence of the presence of organisms [8]. Thus, because this layer actually consisted of two different layers (a case not included in the ICOMOS-ISCS glossary), it could be described as a film, a deposit (the most superficial layer), or a crust (the inner layer), but in no case a patina since exogenic materials are involved. Whatever the term used, none of the present ICOMOS glossary allows for a suitable description of this covering layer.

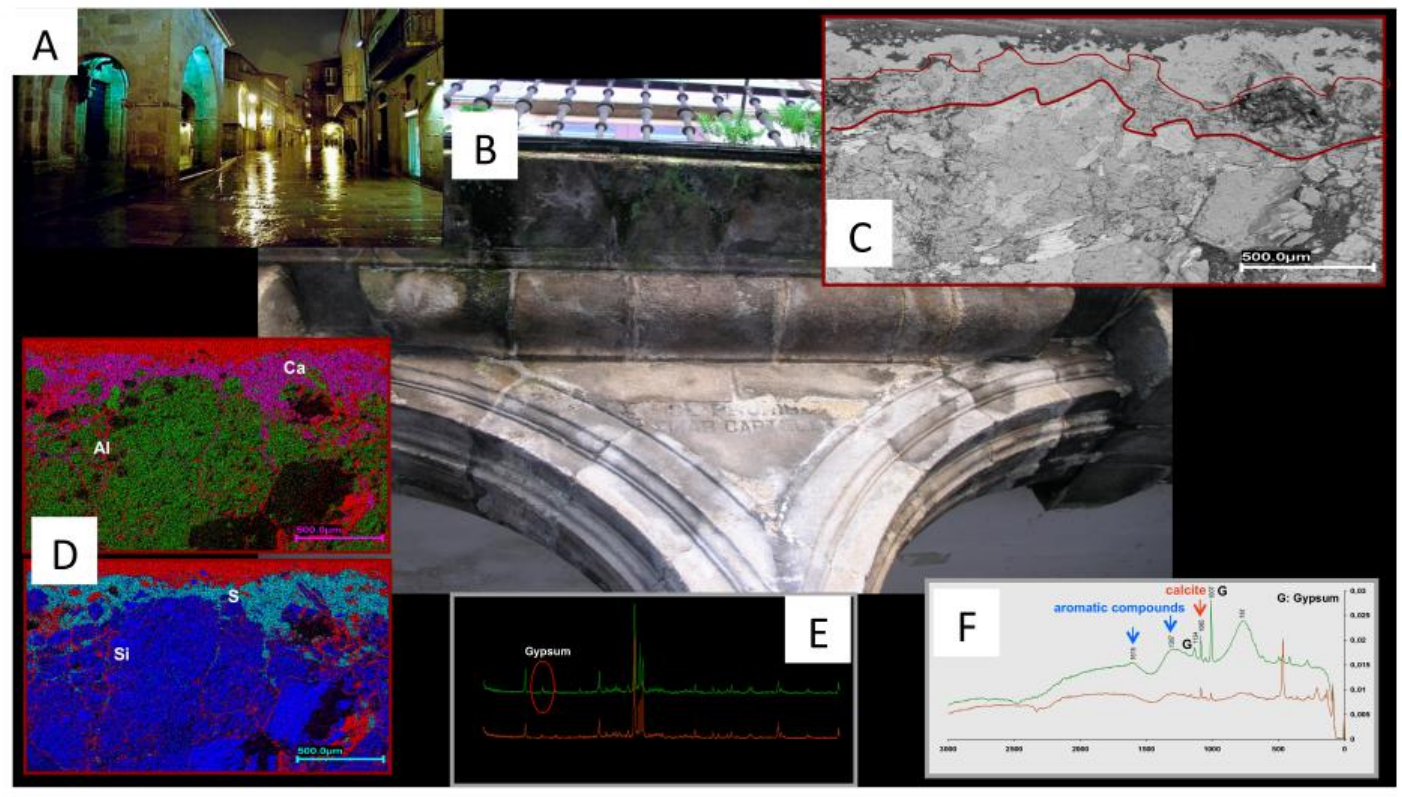

Figure 1. Covering layer on the exterior wall of Number 2 Toural Square (Santiago de Compostela). (A) Entrance to the Toural Square, (B) detail of the sampled area, (C) SEM picture of a cross-section of the covering layer, (D) EDS of the cross-section, (E) XRD spectra of the covering layer (green line) and of the granite underneath the covering layer (brown line), and (F) IR/Raman spectra of the covering layer (green line) and of the granite underneath the covering layer (brown line). 
In the second case (Figure 2), the covering layer from the Monastery of San Martiño Pinario $\left(8^{\circ} 32^{\prime} 40.4^{\prime \prime} \mathrm{W}, 42^{\circ} 52^{\prime} 56.1^{\prime \prime} \mathrm{N}\right.$, WGS84) also seemed to be a patina after on-site identification (Figure 2B). In the lab characterization (Figure 2C,D), it presented $S$ (forming gypsum crystals in their characteristic habit) and $\mathrm{P}$, although it was not possible to determine in what form. In other related studies, the presence of phosphorus was associated with accumulations of apatite, carbonate apatite, and hydroxyapatite [7], and its accumulation was referred to as the deposition of atmospheric particles, the residues left by soaps used in cleaning treatments, the residues of stone conservation treatments based on mixtures of soluble phosphates and silicates, or the mineralization of organic preservatives used in preservation containing phosphorus compounds, especially milk derivatives and casein salts [7]. This may also have a biological origin, as some bacterial colonies increase the phosphate in the solution present in the pores of the rock, causing the local precipitation of apatite, and also, phosphates can come from animal excrements, which is very rich in these compounds. However, apatite can also be present in granite rocks, and $\mathrm{P}$ can also be found in low concentrations in K- and alkali feldspars, and some accessory minerals of granite rocks such as monacite and xenotime, making it difficult to assess if its origin is exogenic or endogenic. In any case, while the observed gypsum and calcite could be exogenous, there are significant doubts about the other components such as $\mathrm{P}$, making it difficult to use the glossary again for this case.

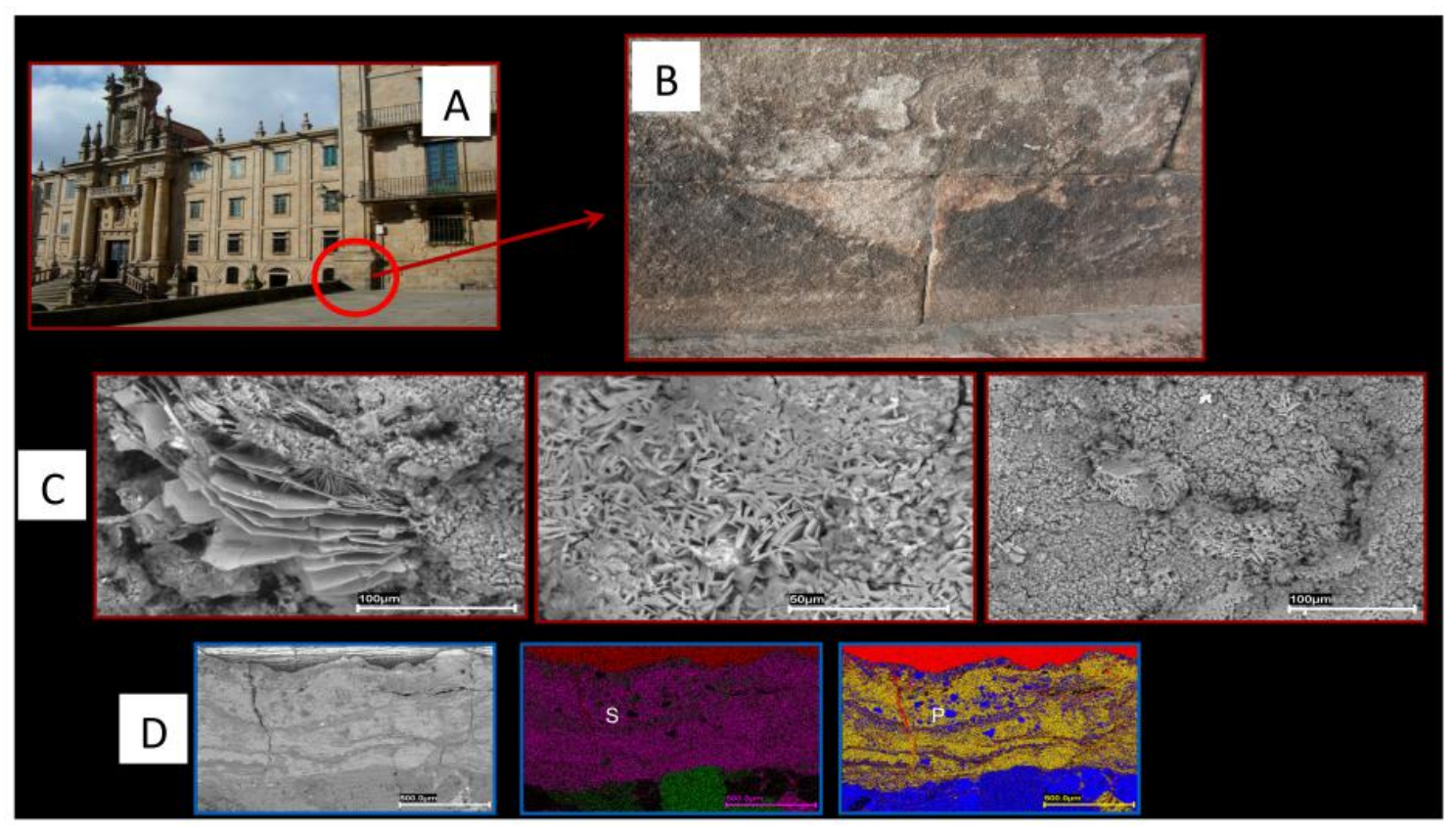

Figure 2. Covering layer on Monastery of San Martiño Pinario (Santiago de Compostela). (A) Area of the wall on the main entrance where the covering layer was taken, (B) detail of the sampled area, (C) SEM pictures of the covering layer, and (D) SEM picture (left) and EDS pictures (middle and right) of the cross-section of the coating.

The third case (Figure 3) concerns a covering layer on the façade of Fonseca Palace $\left(8^{\circ} 32^{\prime} 43.3^{\prime \prime} \mathrm{W}\right.$, $42^{\circ} 52^{\prime} 47.3^{\prime \prime} \mathrm{N}$, WGS84) taken from a sculptural element (Figure 3A). The layer was dark-grey and of a compact, waxen aspect, identified as a patina on site. Examination of samples of the material by electron microscopy revealed two layers of a very different composition to the underlying rock, which were clearly separate from the rock (marked with yellow and orange line segments, Figure 3B). The most superficial layer was of a thickness of about $100 \mu \mathrm{m}$ and the main element was carbon, although some highly electron-reflective particles, mainly composed of $\mathrm{Pb}$, were also detected [5]. Analysis of the material by IR-Raman spectroscopy [7] allowed us to assign the origin to beeswax, which was commonly used in the early 1960s in Galicia to treat the surface of valuable monuments with the aim of preventing the erosive action of atmospheric agents [9]. The inner layer also contained C, along 
with $\mathrm{S}, \mathrm{Ca}, \mathrm{Pb}$, and $\mathrm{Cl}$ (Figure 3C). Examination of samples of the layer by $\mathrm{XRD}$ analysis revealed the presence of gypsum, calcite, portlandite, goethite, and pseudocotumnite (a compound consisting of potassium, lead, and chlorine), as is shown in Figure 3D.

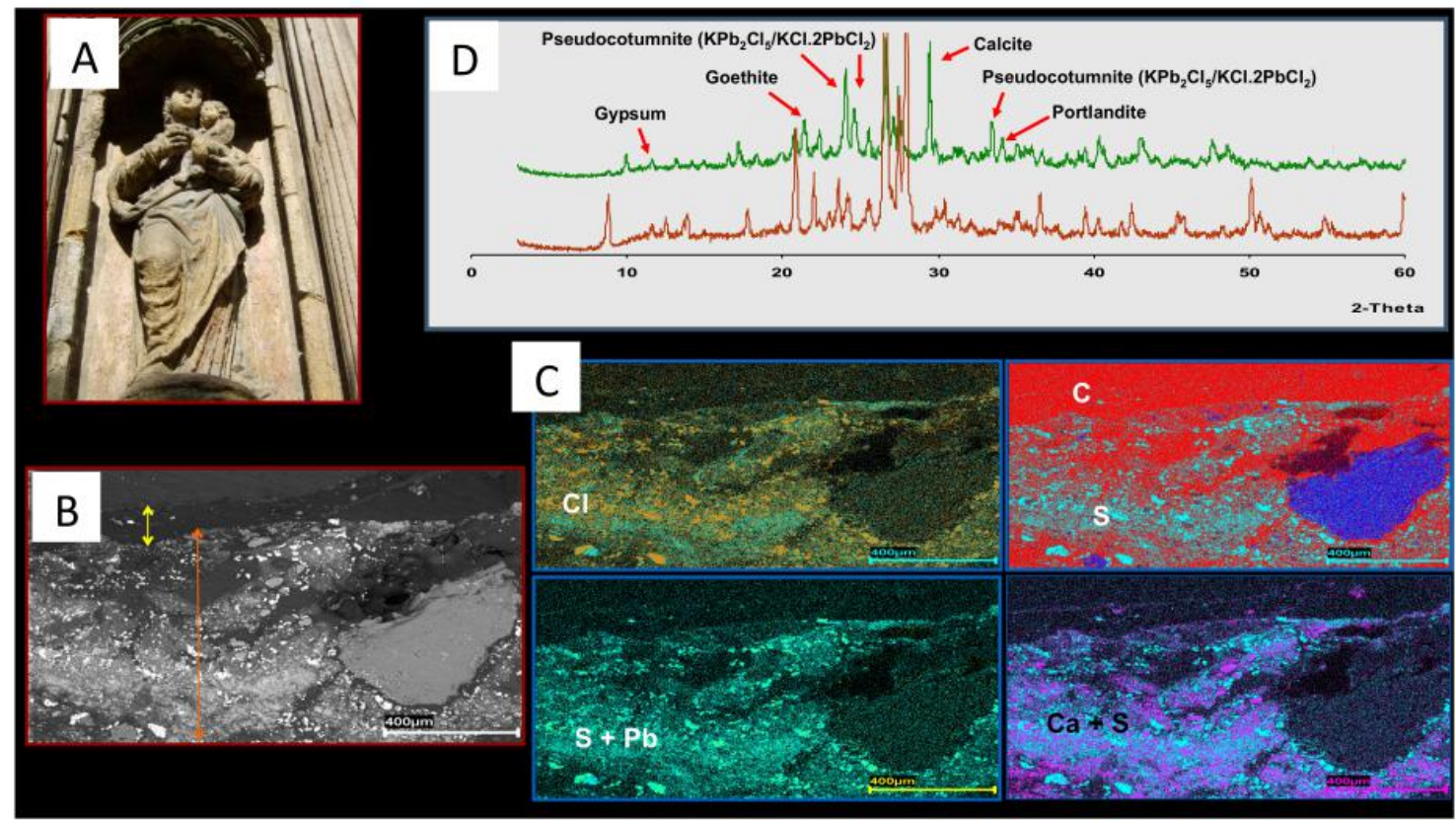

Figure 3. Covering layer on the façade of Fonseca Palace (Santiago de Compostela). (A) Full view of the sculpture where the covering layer was taken, (B) SEM picture of a cross-section of the covering layer, (C) EDS from different zones of the inner layer surface, and (D) XRD spectra of the covering layer (green line) and of the granite underneath the covering layer (brown line).

Taking all of these findings into account, the outer part of this covering layer (but not the inner part) could be described as a film. The inner part could be described as a deposit, crust, or even as soiling, or as none of these.

Case studies of two buildings in the center of the city of A Coruña are also considered: the Church of the Capuchinas $\left(8^{\circ} 23^{\prime} 57.22^{\prime \prime} \mathrm{W}, 43^{\circ} 22^{\prime} 21.45^{\prime \prime} \mathrm{N}\right.$, WGS84) and the Colegiata de Santa Maria del Campo. $\left(8^{\circ} 23^{\prime} 33.26^{\prime \prime} \mathrm{W}, 43^{\circ} 22^{\prime} 14.8^{\prime \prime} \mathrm{N}\right.$, WGS84). Both buildings are made from granite. The layer in question covered most of the main façade of the Church of the Capuchinas (Figure 4A), which overlooks a road with heavy traffic. On site this could be classified as a patina or a film. The layer was dark-grey, porous, and 100-200 $\mu \mathrm{m}$ thick (Figure 4B-D). It was composed of gypsum crystals and airborne soil particles (organic particles and silicate minerals), including particulate air pollution (C-rich spheres, Fe- and -Ba rich aggregates) (Figure 4E,F). It was very difficult to determine whether or not the materials are of completely exogenic origin, and therefore the terms crust, film (as it contains organic carbon), and soiling (the layer has a dirty appearance and contains soot) could all be applied to this covering layer, but not the term patina. 


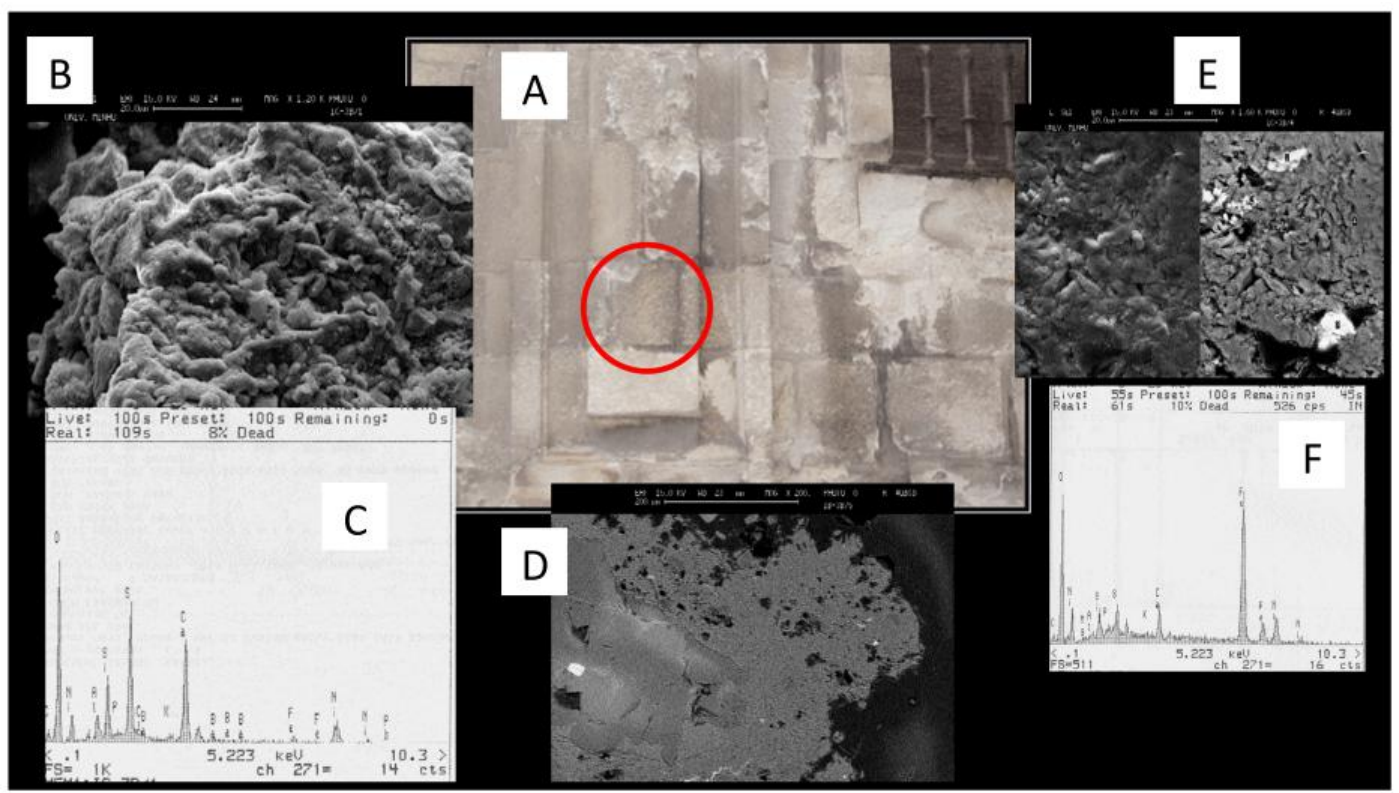

Figure 4. Covering layer on a wall of the Church of the Capuchinas (A Coruña). (A) Area of the wall where the covering layer was taken, (B) surface SEM picture, (C) EDS of the surface, (D) SEM picture of a cross-section of the covering layer, (E) Fe-rich particle, and (F) EDS of the particle.

The covering layer on the south façade of Colegiata de Santa Maria del Campo (Figure 5A) seemed to be a film. It was a dark-grey layer of thickness 100-150 $\mu \mathrm{m}$ (Figure 5B-D). It was composed of airborne soil particles (organic particles and silicate minerals) and gypsum crystals and also contained halite crystals and a Ca-S-C-rich amorphous material. The building is located $200 \mathrm{~m}$ from the coastline and the façade overlooks a road with almost no traffic. The location explains the presence of exogenic halite, but the silicate minerals identified are the same as those found in the underlying granite rock, as observed in other patinas on the same building [10]. Therefore, this cannot be considered to be a film.

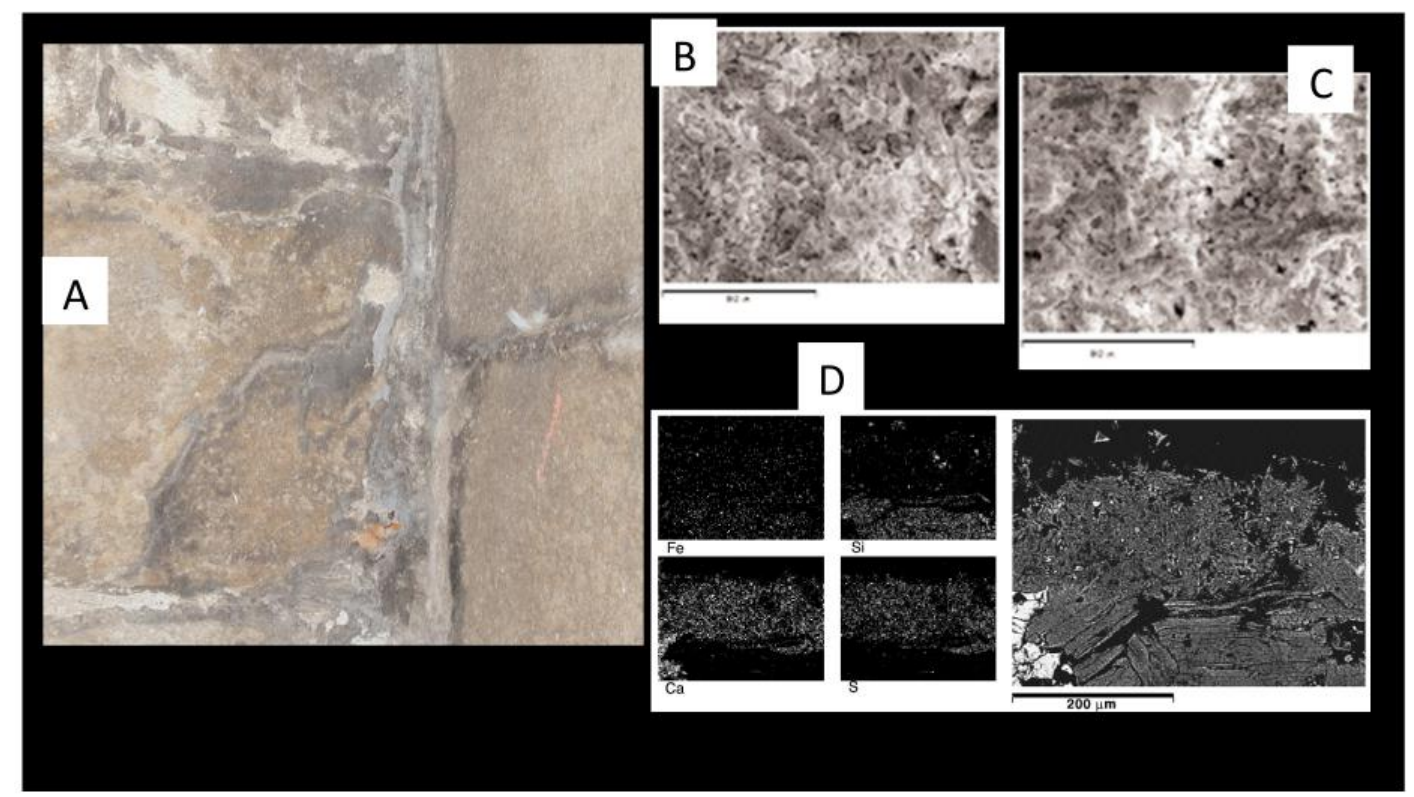

Figure 5. Covering layer on the façade of the Colegiata de Santa Maria del Campo (A Coruña). (A) Detail of the area on the wall where the covering layer was taken, $(\mathbf{B}, \mathbf{C})$ SEM pictures of the covering layer surface, and (D) cross-section and X-ray map of the covering layer. 
The final case considered was a black layer, 100-150 $\mu \mathrm{m}$ thick, on the east façade of the same building (Figure 6A,B). This seemed to be a patina to the naked eye. However, the layer was composed of a porous matrix (Figure 6C) of airborne soil particles (organic particles and silicate minerals), gypsum crystals, halite, and Ba- and Fe-rich aggregates, with traces of P (Figure 6D,E). The building is located $1200 \mathrm{~m}$ from the coastline and the façade overlooks a road with little traffic. Again, it is not easy to assign any of the terms in the ICOMOS-ISCS glossary to this covering layer. This could be a crust, patina, film, or soiling, and, according to a single field observation, it could be classified as a patina.

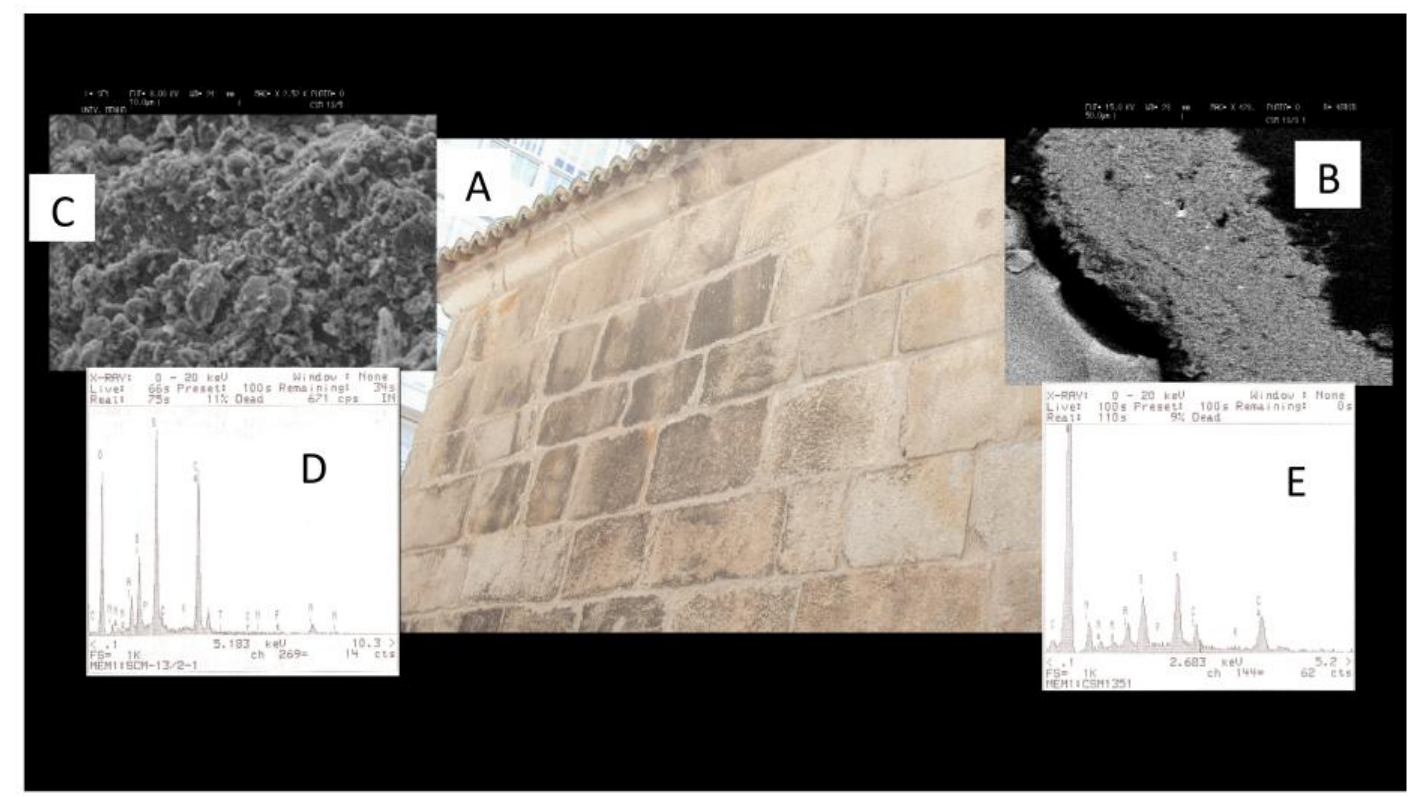

Figure 6. Covering layer on the façade of the Colegiata de Santa Maria del Campo (A Coruña). (A) Full view of the façade where the covering layer was taken, (B) SEM picture of the cross-section of the layer, (C) SEM picture of the surface of the layer, and (D,E) EDS of the layer surface.

\section{Discussion and Final Remarks}

ICOMOS-ISCS illustrated glossary terms are descriptive, therefore notions such as the origin and composition should be avoided as far as possible, since they are not objectively observable characteristics of the deterioration form to the naked eye.

From the characterization of the above covering layers and our observations [5-8,10-12], we can state that the components of most of the covering layers on the granite surfaces are partly related to the surrounding environment and clearly formed from exogenic materials, but also include some of the underlying granite minerals [6,11,12]. Thus, they are not necessarily related to the natural ageing of the rock surfaces and the present term patina is not applicable. Although the term crust could be used, its definition can be used for a variety of light/dark colors and thicknesses of layers, which only sometimes follow the stone surface and that do not contain organic carbon.

In the ICOMOS-ISCS glossary, the term film refers to organic carbon, but our observations for granite are not consistent with the other properties cited in the glossary for films, i.e., "homogeneous" and "follows the stone surface". Soiling and deposit could also be applied, as the samples contain exogenous materials.

The very purpose of an international glossary is to have access to a dedicated tool-kit of precise terms that are accepted, understood, and used by professionals in different contexts. This includes researchers and practitioners of conservation. In that sense, it is important that such a glossary is regularly discussed and updated in order to be adapted to the widest possible range of situations. It is important that the terms can be used on several types of stone, preventing definition overlap. This is particularly problematic in the case of granite rocks, a major construction material in European 
buildings historically [3]. Unlike other porous and reactive rocks (e.g., limestone, marble), granite rocks are not very porous, highly impermeable, and mostly composed of silicate minerals, which react poorly with certain molecules that reach the stone surface (through air or water transport) in urban environments in temperate climates.

Many studies on the coatings found on granite surfaces of historical buildings show a mixture of exogenous and endogenous particles, such as carbonaceous or S- and P- rich particles. In such cases, the term patina from the glossary cannot be applied. The use of the other terms is also problematic: carbonaceous particles are not necessary organic, as the definition of film requires, or not necessarily all components of the coating are exogenous, as the definition of deposit shows. Sometimes other terms, such as soiling, cannot be applied because dust coatings combine endogenous and exogenous particles. Thus, in granite rocks only the term crust is applicable for the characterization of most coatings.

In conclusion, we suggest a review of the five terms in the ICOMOS-ISCS glossary, thus opening a debate with the the possibility of redefining some of the terms, or at least some aspects of these terms. The addition of new terms would help make the glossary more clear and useful in the future for all stone types, including granite rocks. The purpose of this revision would be to compile a glossary applicable to all study cases. If not, there is the risk that the glossary will fall out of use, being useless for both researchers and practitioners when applied to certain rock types, such as granite. A new glossary should consider that some materials and surfaces are more prone to react with exogenous particles, and so all the terms are not applicable in the same manner to all materials and study cases. Of course, any future review of the terms should be based on a complete overview of the covering layers described on granite rocks, which is beyond the scope of this paper.

Author Contributions: Conceptualization, P.S., J.S.-S., B.P.; writing-original draft preparation, P.S, J.S.-S.; writing-review and editing, P.S., J.S.-S., B.P. All authors have read and agreed to the published version of the manuscript.

Funding: The authors are grateful for funding from the Xunta de Galicia within the projects "Consolidación y estructuración de unidades de investigación competitivas-Grupos de referencia competitiva (GRC)" (Ref. ED431C 2018/32) and "Consolidación y estructuración de unidades de investigación competitivas-Grupos de potencial crecimiento (GPC)" (Ref. GPC2015/024).

Conflicts of Interest: The authors declare no conflict of interest.

\section{References}

1. Dorn, R.I. Rock Coatings; Elsevier: Amsterdam, The Netherlands, 1998.

2. Vergès-Belmin, V. (Ed.) Illustrated Glossary on Stone Deterioration Patterns; Monuments and Sites XV; ICOMOS: Paris, France, 2008.

3. Vicente, M.A.; Delgado Rodrigues, J.; Acevedo, J. Degradation and Conservation of Granitic Rocks in Monument; Protection and Conservation of the European Cultural Heritage Research Report No. 5; European Commission: Brussels, Belgium, 1996.

4. Martínez-Cortizas, A.; Pérez-Alberti, A. (Eds.) Atlas Climático de Galicia; Consellería de Medioambiente: Xunta de Galicia, Spain, 1999.

5. Prieto, B.; Aira, N.; Silva, B. Comparative study of dark patinas on granitic outcrops and buildings. Sci. Total Environ. 2007, 381, 280-289. [CrossRef]

6. Sanjurjo-Sánchez, J.; Romaní, J.R.V.; Alves, C. Comparative analysis of coatings on granitic substrates from urban and natural setings (NW Spain). Geomorphology 2012, 138, 231-242. [CrossRef]

7. Aira, N. Pátinas Oscuras Sobre Rocas Graníticas: Génesis y Composicioén. Ph.D. Thesis, University of Santiago de Compostela, Santiago de Compostela, Spain, 2007.

8. Aira, N.; Jurado, V.; Prieto, B.; Silva, B. Gas chromatography applied to cultural heritage. Analysis of dark patinas on granite surfaces. J. Chromatogr. A 2007, 1147, 79-84. [CrossRef] [PubMed]

9. Pan, A.; Chiussi, S.; Serra, J.; González, P.; León, B. Excimer laser removal of beeswax from galician granite monuments. J. Cult. Herit. 2009, 10, 48-52. [CrossRef] 
10. Sanjurjo Sánchez, J.; Vidal Romani, J.R.; Fernández Mosquera, D.; Alves, C.A. Study of origin and composition of coatings in a monument built with granitic rocks, by SEM, XRD, XRF and DTA-TGA. X-ray Spectrom. 2008, 37, 346-354. [CrossRef]

11. Sanjurjo-Sánchez, J.; Romaní, J.R.V.; Alves, C. Deposition of particles on gypsum-rich coatings of historic buildings in urban and rural environments. Constr. Build. Mater. 2011, 25, 813-822. [CrossRef]

12. Sanjurjo-Sánchez, J. La Secuencia de Alteración de Superficies Graníticas: Influencia de Factores Litológicos, Geodinámicos, Climáticos y Biológicos. Ph.D. Thesis, University of A Coruña, A Coruña, Spain, 2005.

(C) 2020 by the authors. Licensee MDPI, Basel, Switzerland. This article is an open access article distributed under the terms and conditions of the Creative Commons Attribution (CC BY) license (http://creativecommons.org/licenses/by/4.0/). 